\title{
Dive depth and plumage air in wettable birds: the extraordinary case of the imperial cormorant
}

\author{
Flavio Quintana ${ }^{1, *}$, Rory P. Wilson ${ }^{2}$, Pablo Yorio ${ }^{1}$ \\ ${ }^{1}$ Centro Nacional Patagónico, CONICET (9120) Puerto Madryn, Chubut and Wildlife Conservation Society, \\ 2300 Southern Boulevard, Bronx, New York 10460, USA \\ ${ }^{2}$ Biological Sciences, Institute of Environmental Sustainability, University of Wales, Swansea SA2 8PP, UK
}

\begin{abstract}
Cormorants are considered to be remarkably efficient divers and hunters. In part, this is due to their wettable plumage with little associated air, which allows them to dive with fewer energetic costs associated with buoyancy from air in the feathers. The literature attributes particularly exceptional diving capabilities to cormorants of the 'blue-eyed' taxon. We studied the diving behaviour of 14 male imperial cormorants Phalacrocorax atriceps (included in the blue-eyed taxon) in Patagonia, Argentina, and found that this species did indeed dive deeper, and for longer, than most other non-blue-eyed cormorant species. This species also exhibited longer dive durations for any depth as well as longer recovery periods at the surface for particular dive durations. We propose that this, coupled with atypically long foraging durations at sea in cold water, suggests that cormorants of the blue-eyed complex have a plumage with a substantial layer of insulating air. This is given credence by a simple model. High volumes of plumage air lead to unusually high power requirements during foraging in shallow, warmer waters, which are conditions that tend to favour wettable plumage. However, deep dives and/or cold water should favour the blue-eyed phenotype, which explains their essentially high latitude distribution.
\end{abstract}

KEY WORDS: Diving behaviour · Cormorants $\cdot$ Patagonia $\cdot$ Argentina $\cdot$ Buoyancy $\cdot$ Insulation

\section{INTRODUCTION}

Cormorants are cosmopolitan fish-eating aquatic predators and members of the 39 species that comprise the genus Phalacrocorax (Orta 1992). They frequent both coastal and inland waters from polar to tropical regions, breeding in colonies numbering from just a few individuals to many thousands of birds (Johnsgard 1993). The obvious success of this group has been attributed to their efficiency as aquatic predators (Gremillet et al. 2001, 2005a), this being related to their swimming and diving abilities (Gremillet 1997, Gremillet et al. 2004) that are, in part, a result of their wettable plumage (Ribak et al. 2005, Gremillet et al. 2005b), which results in reduced buoyancy. Despite this, cormorants are often cited as diving shallowly, primarily exploiting the first $10 \mathrm{~m}$ of the water column in dives that rarely exceed 1 min (for review see Cooper 1986). A notable exception to this appears to be the blue-eyed, Southern Ocean cormorants (also called shags), which consist of 13 taxa (Orta 1992). To date, aspects of the diving behavior of blue-eyed cormorants have been described for birds mainly from sub-Antarctic colonies using data derived from radiotelemetry (Wanless et al. 1992, Sapoznikow \& Quintana 2003) and time-depth recorders (Croxall et al. 1991, Kato et al. 1996, 2000, Wanless et al. 1999, Tremblay et al. 2005). These data indicate that blueeyed cormorants are indeed exceptional divers, their current maximum recorded depth being $145 \mathrm{~m}$ (Tremblay et al. 2005) and maximum duration being $380 \mathrm{~s}$ (Wanless et al. 1992).

Given that blue-eyed cormorants appear morphologically very similar to other members of the genus, it is 
not immediately obvious why their apparent diving ability should be greater than that of congeners. In this study, we documented the diving behavior of 14 male imperial cormorants Phalacrocorax atriceps breeding in Patagonia, Argentina, using time-depth recorders. We examined these and other published data on dive performance by members of the Phalacrocoracidae to examine the extent to which these birds really are exceptional among cormorants, and attempted to explain the patterns observed. For this, we used standard simple models describing how plumage air thickness varies with depth (cf. Wilson et al. 1992, Gremillet et al. 1998b), and how this relates against buoyancy and energy lost as heat. We noted that aspects of our data set were previously published (Wilson \& Quintana 2004) in a discussion of other matters not directly relevant to this work.

\section{MATERIALS AND METHODS}

Fieldwork was conducted at 2 sites in coastal $\mathrm{Chu}$ but, Argentina: Caleta Malaspina $\left(45^{\circ} 11^{\prime} \mathrm{S}, 66^{\circ} 30^{\prime} \mathrm{W}\right)$ between 3 and 20 December 2001, and Punta León $\left(43^{\circ} 04^{\prime} \mathrm{S}, 64^{\circ} 2^{\prime} \mathrm{W}\right)$ between 1 and 4 December 2003. The former is an inlet of $34 \mathrm{~km}^{2}$, with a maximum width of $4 \mathrm{~km}$ and length of $10 \mathrm{~km}$. The imperial cormorants breed at 2 islands: Vernaci Este (VE) at the mouth of the inlet, and Vernacci Oeste (VO) inside the inlet, separated by $2.2 \mathrm{~km}$. Yorio et al. (1998) reported 375 and 298 pairs of imperial cormorants breeding at VE and VO, respectively. At Punta León, a silt platform of approximately 5 ha lying seaward of the $100 \mathrm{~m}$ tall cliffs provides nesting habitat for several seabird species, including approximately 3050 imperial cormorant pairs (Yorio et al. 1998).

Time-depth recorders (TDR Mk7, Wildlife Computers) were deployed on 15 adult male imperial cormorants ( 7 at VE and 8 at VO) during the first $10 \mathrm{~d}$ of the chick-rearing period. Male imperial cormorants were sexed by vocalizations (males 'honk' and females 'hiss', see Malacalza \& Hall 1988). The TDRs measured $10 \times 2 \times 1 \mathrm{~cm}$ and weighed $30 \mathrm{~g}$, less than $1.5 \%$ of adult body mass (mean: 2400 g; range: 2200 to $2500 \mathrm{~g}$ ). Devices were attached to the feathers using waterproof tape and 2 cable-ties in the centre/lower back to minimize hydrodynamic drag (Bannasch et al. 1994). The procedure was completed in less than 5 min and birds quickly returned to their nest. All birds carrying devices continued to breed normally during the study period. Depth data were recorded with a resolution of $0.5 \mathrm{~m}$ at $1 \mathrm{~Hz}$. Birds were recaptured after several foraging trips ( 1 to 10 , undertaken during periods of between 1 and $5 \mathrm{~d}$ ), the TDRs removed and the data downloaded.
Four birds, 1 female and 3 males, were equipped with other TDRs (high resolution DK 16-D series, Driesen and Kern) at Punta León. The devices were attached in the same way as those of Wildlife Computers and recovered (when possible) after a single foraging trip. The units recorded depth with a resolution better than $1 \mathrm{~cm}$ at a frequency of $10 \mathrm{~Hz}$. These units were deployed specifically to determine stroking frequency as a function of depth, in order to estimate the potential effect that buoyancy might have on the foraging ecology of this species.

Data obtained from the Wildlife Computer TDRs were analyzed using the programme MTDIVE (Jensen Software Systems). This programme graphically displays depth data against time, and then places cursors at the start and end of dives as well as at points of inflection in the dive profile to indicate the initiation and end of the bottom phase when birds forage along the seabed. The appropriateness of the cursor positions was checked visually before data were written to an ASCII spreadsheet, with the following parameters for each dive being determined: time of initiation of each dive, duration and rate of the descent, bottom and ascent phases, and maximum depths reached during the dive. Pelagic dives were defined as V-shaped dives, with bottom durations of less than or equal to $2 \mathrm{~s}$ (twice the recording interval of the TDRs), whereas benthic dives were defined as U-shaped dives, with bottom durations of at least $3 \mathrm{~s}$.

Differences among individuals with regard to diving (e.g. depth, dive duration, surface duration etc.) were tested using a Kruskal-Wallis test or 1-way ANOVA, depending on normality. In all cases, differences among individuals were significant to at least the $p<0.05$ level or better. Mean values for all parameters were determined for each bird and then pooled to calculate overall mean $( \pm \mathrm{SD})$.

Depth data recorded by the high resolution DK 16D devices were analyzed using the program MT-WIN (Jensen Software Systems). This programme displays data in much the same way as MTDIVE (see above), but the data can be assessed so as to derive rates of change in depth $(\Delta D / \Delta t$, where $t$ is time) in order to look for periods of acceleration and deceleration corresponding to kicks used in swimming.

\section{RESULTS}

All TDRs deployed were successfully recovered from the 15 birds equipped at Caleta Malaspina. However, 1 instrument failed, and data could not be downloaded for 1 of 8 cormorants from VO. The maximum deployment period was $9 \mathrm{~d}$, during which diving activity could be recorded for up to $5 \mathrm{~d}$ before the memory was 
full. No instrumented birds lost chicks during the study period. A data set of 56 bird-days at sea was obtained, consisting of almost $240 \mathrm{~h}$ of diving activity that represented 2993 dives distributed over 91 foraging trips of the 14 cormorants (Table 1 ).

Birds generally performed between 1 and 2 foraging trips per day. Mean number of dives per day was $54.3 \pm 29.7$ ( $\mathrm{n}=26 \mathrm{~d}, 14$ birds). The maximum number of dives per day was 126 . However, days with more than 100 dives were infrequent and constituted less than $8 \%$ of the data. The cormorants were almost exclusively diurnal feeders, foraging from dawn to dusk. However, most dives (84\%) were initiated after 13:00 h. Almost $50 \%$ of dives were made after 18:00 h and diving activity lasted until a maximum of $52 \mathrm{~min}$ after sunset (21:10 h).

Imperial cormorants foraged over a wide range of depths. Although maximum dive depth was bimodally distributed with modes around 5 to $10 \mathrm{~m}$ and 25 to $30 \mathrm{~m}$, over $50 \%$ of all dives were directed to depths in

Table 1. Phalacrocorax atriceps. Summary statistics from diving records of 14 male imperial cormorants breeding at Patagonia, Argentina. Data are mean \pm SD (max.)

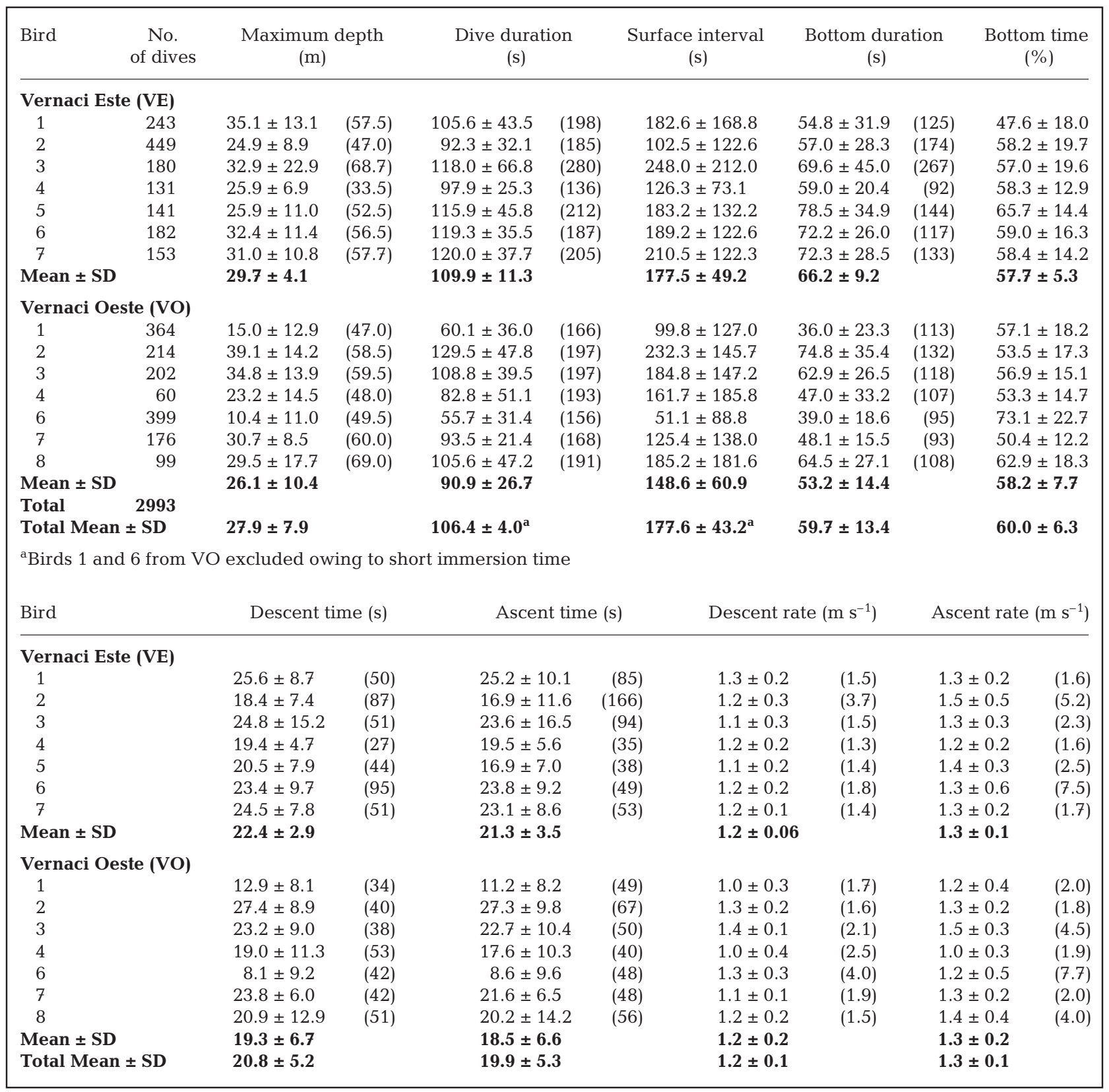


excess of $28 \mathrm{~m}$ (Fig. 1A). Mean maximum dive depths of birds were similar between colonies (Mann-Whitney $U$-test, $Z=0.7)$. Mean maximum dive depth was $27.9 \mathrm{~m}$ (SD 7.9, $\mathrm{n}=14$ birds, 2993 dives). The maximum depth recorded for any bird was $69 \mathrm{~m}$ (Table 1). Maximum depth reached during a dive was highly and positively correlated with total dive duration, according to a linear function where:

$$
\text { duration }=26.2+2.6 D\left(r^{2}=0.77, p<0.05\right)(\text { Fig. } 2 \mathrm{~A})
$$

where $D$ is depth $(\mathrm{m})$. Mean dive duration was $106 \mathrm{~s}$ (SD $4 \mathrm{~s}, \mathrm{n}=12$ birds), but all cormorants executed some dives that lasted more than $120 \mathrm{~s}$, with over $50 \%$ of all dives exceeding $100 \mathrm{~s}$ (Fig. 1B). Maximum dive duration recorded was $280 \mathrm{~s}$ (Table 1). Mean time at the surface between successive dives (surface duration), excluding prolonged surface intervals (i.e. those in excess of $15 \mathrm{~min}$ [900 s, which constituted only $2 \%$ of total surface intervals]), was $178 \mathrm{~s}$ (see Table 1). Despite considerable variance, there was a clear relationship between the time taken at the surface between
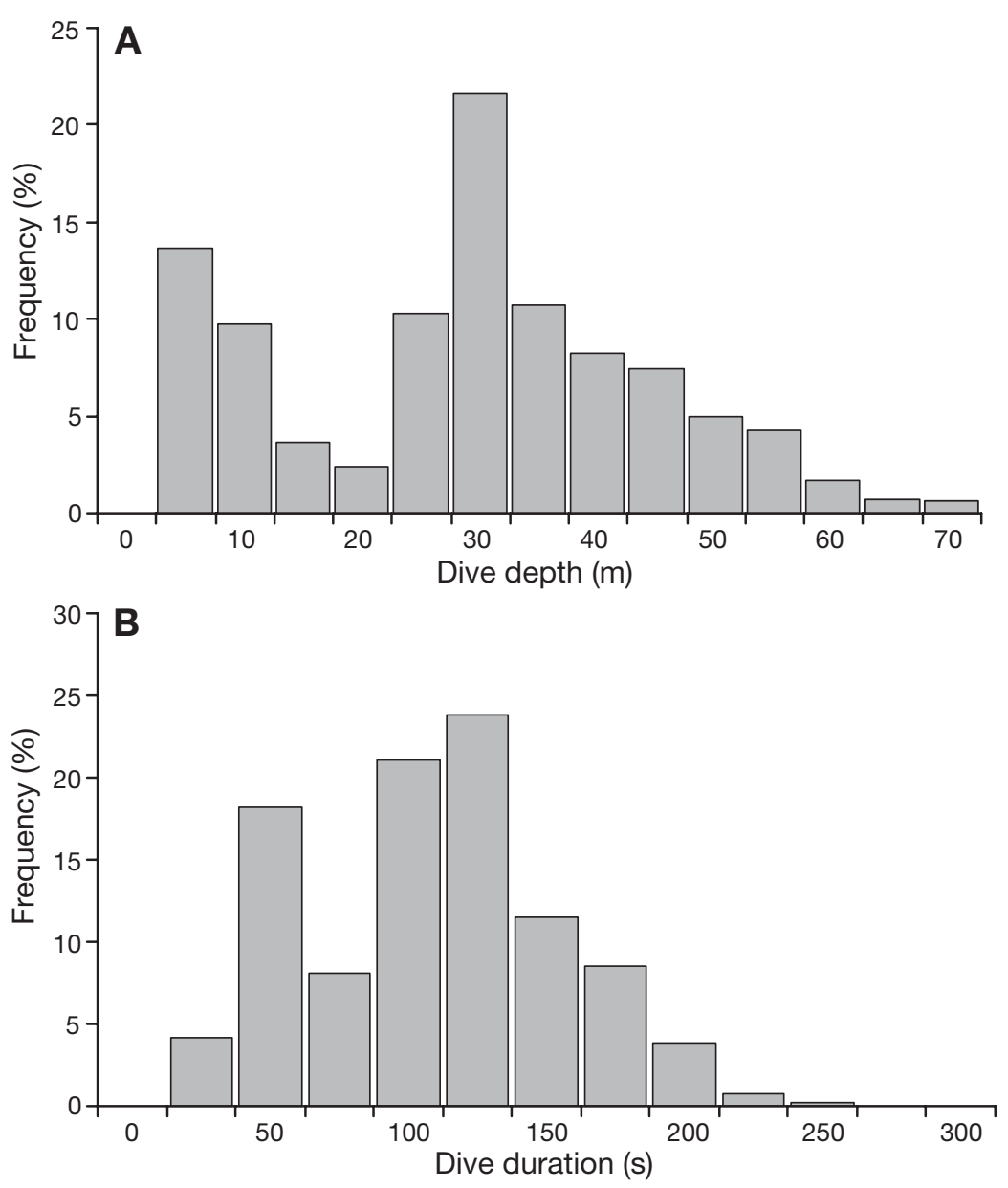

Fig. 1. Phalacrocorax atriceps. Frequency distribution of (A) maximum dive depths and (B) maximum dive duration of imperial cormorants foraging over the Patagonian Shelf, Argentina ( $\mathrm{n}=14$ birds, $\mathrm{n}=2293$ dives) dives and the maximum dive depth reached in the preceding dive, with the relationship being best described by:

surface pause duration $=19.5 \mathrm{e}^{0.05 D}\left(\mathrm{r}^{2}=0.58\right.$,

$$
\mathrm{p}<0.0001 \text { ) (Fig. 2B) }
$$

During dives, the duration of the descent was slightly greater than that of the ascent phase $(20.8 \pm 5.2$ vs. 19.9 $\pm 5.3 \mathrm{~s}$ ) (Wilcoxon matched pairs test, $Z=2.5, \mathrm{p}<0.05$, $\mathrm{n}=14$ birds) (Table 1 ). Both diving variables were related to maximum dive depth according to linear regressions:

$$
\text { descent duration }=2.5+0.65 D\left(r^{2}=0.89, p<0.05\right)
$$

and

$$
\text { ascent duration }=1.7+0.65 D\left(\mathrm{r}^{2}=0.68, \mathrm{p}<0.05\right)
$$

Vertical velocities for descent and ascent (measured as rates of change in depth during the descent and ascent phases) were independent of depth during any single descent/ascent (cf. Fig. 3) and were 1.2 \pm 0.1 and $1.3 \pm 0.1 \mathrm{~m} \mathrm{~s}^{-1}$, respectively $(\mathrm{n}=7$ birds per colony) and were poorly correlated with the maximum depth of dives $(r=0.3$ and 0.2 for descent and ascent velocities, respectively, $\mathrm{p}<0.05$ ).

During $95 \%$ of dives, the cormorants spent extended time at a particular maximum depth, giving a U-shaped dive profile (see 'Materials and methods'). In 5\% of dives, and in all individuals, birds dived to a specific depth before returning virtually immediately to the surface (V-shaped). Maximum dive depth, dive duration, descent and ascent vertical velocities were significantly lower for $\mathrm{V}$-dives than for U-dives (Mann-Whitney $U$-test, $Z=9.0,14.4,13.6$ and 15.5 , respectively $\mathrm{p}<0.01$ ).

Mean bottom duration was almost $1 \mathrm{~min}$ $(59.7 \pm 13.4 \mathrm{~s}, \mathrm{n}=14$ birds). The maximum duration spent foraging at the seabed during any one dive was $267 \mathrm{~s}$, and all birds performed dives where they spent in excess of $91 \mathrm{~s}$ at the bottom. There was a positive relationship between the amount of time spent at the point of maximum depth in U-shaped dives (bottom duration) and maximum dive depth, according to:

$$
\begin{aligned}
\text { bottom duration } & =25.9+1.25 D\left(r^{2}=0.38\right. \\
p & <0.0001)
\end{aligned}
$$

Of the 4 birds equipped with high resolution depth loggers (DK 16) at Punta León, 1 malfunctioned due to water ingression. The memory of 2 others was full before systematic, 
deep diving was undertaken, so that these devices only recorded short shallow dives to a maximum of $9 \mathrm{~m}$ (which appeared to be largely exploratory, rather than foraging, dives). However, 1 unit recorded all dives for a full foraging period of 365 min. Relationships between total dive duration, descent duration, bottom duration, ascent duration, and maximum depth reached during dives were within the $95 \%$ confidence limits of the birds from Caleta Malaspina. This unit showed systematic variation in the descent rate (Fig. 3A), which we interpreted as being due to the foot kicks used in propulsion. These kicks were most apparent during the descent (Fig. 3A), where they decreased in frequency with increasing depth (Fig. 3B).

\section{DISCUSSION}

Our results show that imperial cormorants routinely dive to depths in excess of $20 \mathrm{~m}$ and for longer than $100 \mathrm{~s}$ (Fig. 1), which appears excessive for cormorants in general (Cooper 1986). However, if species-specific maxima are considered, our results, together with others previously published, indicate that members of the blue-eyed cormorant complex dive both deeper
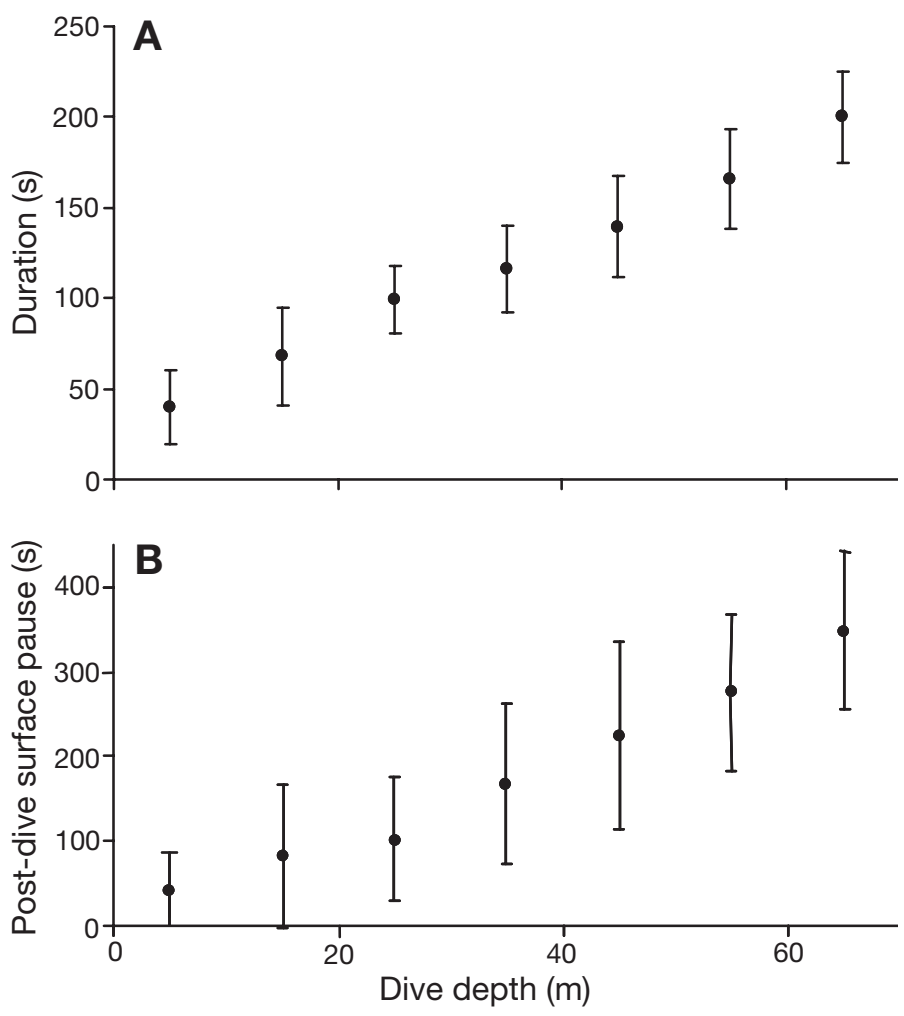

Fig. 2. Phalacrocorax atriceps. Relationship between (A) total dive duration and (B) post-dive surface pause duration and maximum dive depth for imperial cormorants foraging over the Patagonian Shelf, Argentina ( $\mathrm{n}=14$ birds, $\mathrm{n}=2293$ dives). Data are mean per depth class $\pm \mathrm{SD}$
(Fig. $4 \mathrm{~A}_{i} t=4.25, \mathrm{p}<0.005$ ) and longer (Fig. $4 \mathrm{~B}_{;} t=7.24$, $\mathrm{p}<0.001)$ than other cormorant species. Species mass is indicated in the figures because the effects of allometry are considered important in dive capacities (Schreer \& Kovacs 1997, Schreer et al. 2001). We note however that phylogenetic information should ideally be included (Halsey et al. 2006), something that we did
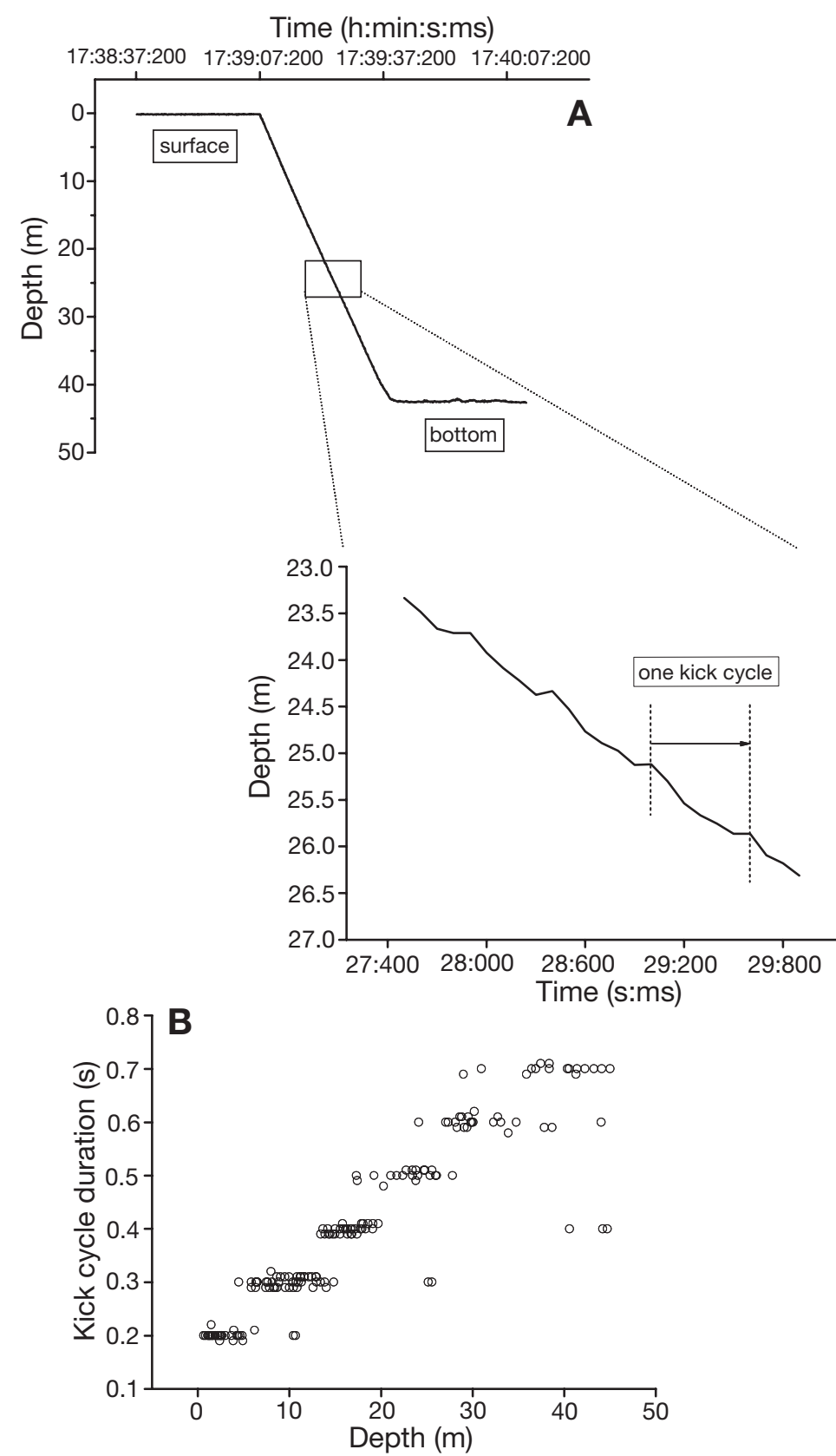

Fig. 3. Phalacrocorax atriceps. (A) Section of the descent and bottom phase of a dive (depth vs. time) made by an imperial cormorant to $43 \mathrm{~m}$, with an enlarged inset of $\sim 25 \mathrm{~m}$ depth to show systematic variation attributed to kicks used in descent. (B) Relationship between kick cycle duration and depth in the same bird during a series of 13 dives, all executed to a maximum depth of $46 \mathrm{~m}$ 

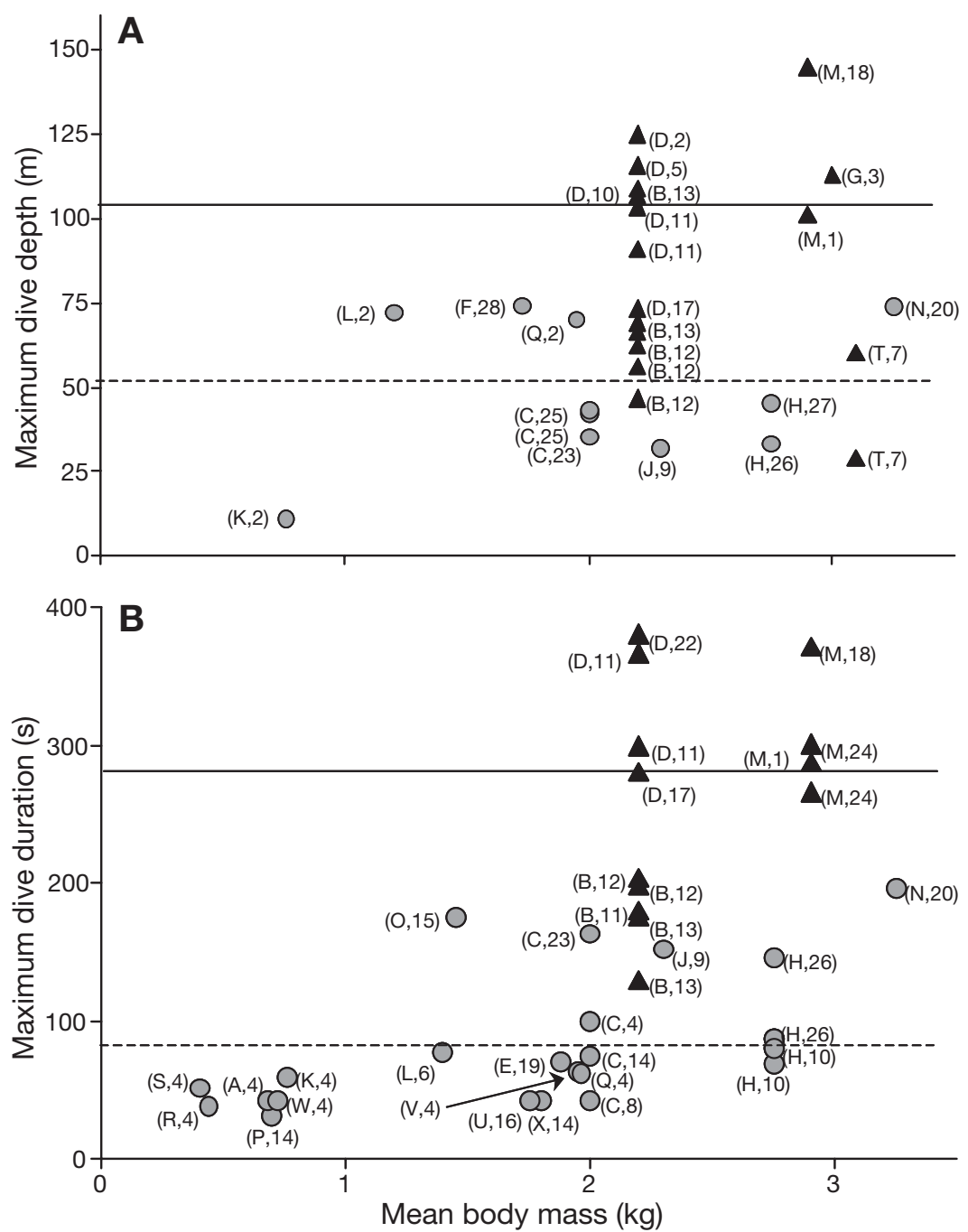

Fig. 4. Mean maximum (A) dive depth and (B) dive duration of various cormorant species. Horizontal lines are blue-eyed cormorant mean (solid line) and non-blue-eyed cormorant mean (dashed line); all values calculated from species (rather than study site) maxima. Depths derived only from records of depth gauges attached to birds: records from nets are equivocal because birds can be caught while the net is being lowered. Where depth values from the literature were only given as mean $\pm \mathrm{SD}$, maxima were approximated by mean $+2 \mathrm{SD}$. Durations were derived from depth gauges, VHF telemetry or visual observation. Masses are medians from Orta (1992) or unpubl. data. $\mathbf{A}$ blue-eyed cormorants; O: non-blue-eyed cormorants; A, Phalacrocorax africanus; $\mathrm{B}, P$. albiventer $; \mathrm{C}, P$. aristotelis; $\mathrm{D}, P$. atriceps; E, P. auritus F, $P$. bougainvillii; $G, P$. bransfeldensis; $H, P$. capillatus; $I, P$. capensis;

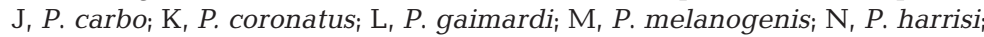
$\mathrm{O}$, P. magellanicus; $\mathrm{P}, \mathrm{P}$. melanoleucas; $\mathrm{Q}, P$. neglectus; $\mathrm{R}, P$. niger $\mathrm{S}$, P. nigrogularis; $\mathrm{T}$, P. nivalis; $\mathrm{U}$, P. olivaceous; $\mathrm{V}$, P. pelagicus; $\mathrm{W}, P$. pygmeus; $\mathrm{X}, P$. varius. Numbers refer to source data: 1 , Bevan et al. (1997); 2, Burger (1991); 3, Casaux et al. (2001); 4, Cooper (1986); 5, Croxall et al. (1991); 6, Frere et al. (2002); 7, Green \& Williams (1997); 8, Gremillet et al. (1998a); 9, Gremillet \& Wilson (1999); 10, Ishikawa \& Watnuki (2002); 11, Kato et al. (1992); 12, Kato et al. (1996); 13, Kato et al. (2000); 14, Lea et al. (1996); 15, Quintana (1999); 16, Quintana et al. (2004); 17, this study; 18, Tremblay et al. (2005); 19, data from http://www.inhs.uiuc.edu/chf/ pub/ifwis/birds/double-crested-cormorant.html; 20, H. Vargas (unpubl. data); 21, Wanless \& Harris (1991); 22, Wanless et al. (1992); 23, Wanless et al. (1993); 24, Wanless et al. (1995); 25, Wanless et al. (1999); 26, Watanuki et al. (1996); 27, Wilson \& Wilson (1988); 28, Zabalaga \& Paredes (1999). Doubled species with authors refer to inter-sex or inter-locality differences. Arrow indicates data point $\mathrm{V}, 4$ not attempt owing to uncertainties in cormorant phylogeny (Orta 1992). Although the birds we equipped did not achieve depths or durations equivalent to some of the sub-Antarctic imperial cormorants, they were apparently precluded from diving deeper because they were foraging over the shallow Patagonian Shelf. Inclusion of data that give information on dive duration in relation to depth partially negates this problem, and shows quite clearly that imperial cormorants stand out in having a generally longer dive duration for any given depth than non-blue-eyed species (Fig. 5A). However, this performance in terms of duration is apparently mirrored by excessively long recovery periods at the surface following dives (Fig. 5B). Clearly, birds of the blue-eyed complex are different from other cormorants, and we speculate on why this is by discussing what is known about bird physiology and standard physics (see below).

Firstly, why do imperial cormorants take so long to recover from dives (Fig. 5B)? The surface recovery period is necessary for divers to acquire the oxygen lost during the dive (as well as to clear carbon dioxide), and if the recovery period is excessively long, the implication is that correspondingly larger amounts of oxygen have been used during the dive (Wilson \& Quintana 2004); however, the excessive surface durations after exceptionally long dives may also be due to an increasing anaerobic component of the dive. Since oxygen use is considered a proxy for metabolic rate (Schmid et al. 1995, Schmidt-Nielsen 1997, Enstipp et al. 2006), it might seem reasonable to suppose that imperial cormorants use more energy for their dives, at least in the duration range where they can be compared with other species. There are 4 major features that modulate metabolic rate in diving cormorants: water temperature (Enstipp et al. 2005, 2006), speed (Schmid et al. 1995, Lovvorn et al. 2004), the heat increment of feeding (Enstipp et al. 2005, 2006) and dive depth (Enstipp et al. 2006). The proportion of energy allocated to the heat increment of feeding is unlikely to differ among species because cormorants are primarily piscivores (Johnsgard 1993), and birds should be ingesting an approximately constant percentage of 
their body mass and using a corresponding amount of energy to digest it.

The descent speed of cormorants is generally high ( 0.8 to $1.5 \mathrm{~m} \mathrm{~s}^{-1}$ ) but constant, with no obvious difference between blue-eyed and other cormorants (Croxall et al. 1991, Watanuki et al. 1996, Kato et al. 2006, Watanuki et al. 2006). Superficially, at least, temperature does not appear to be important in accounting for the difference either, because the imperial cormorants we studied in Argentina were operating in water at temperatures similar to those experienced by other
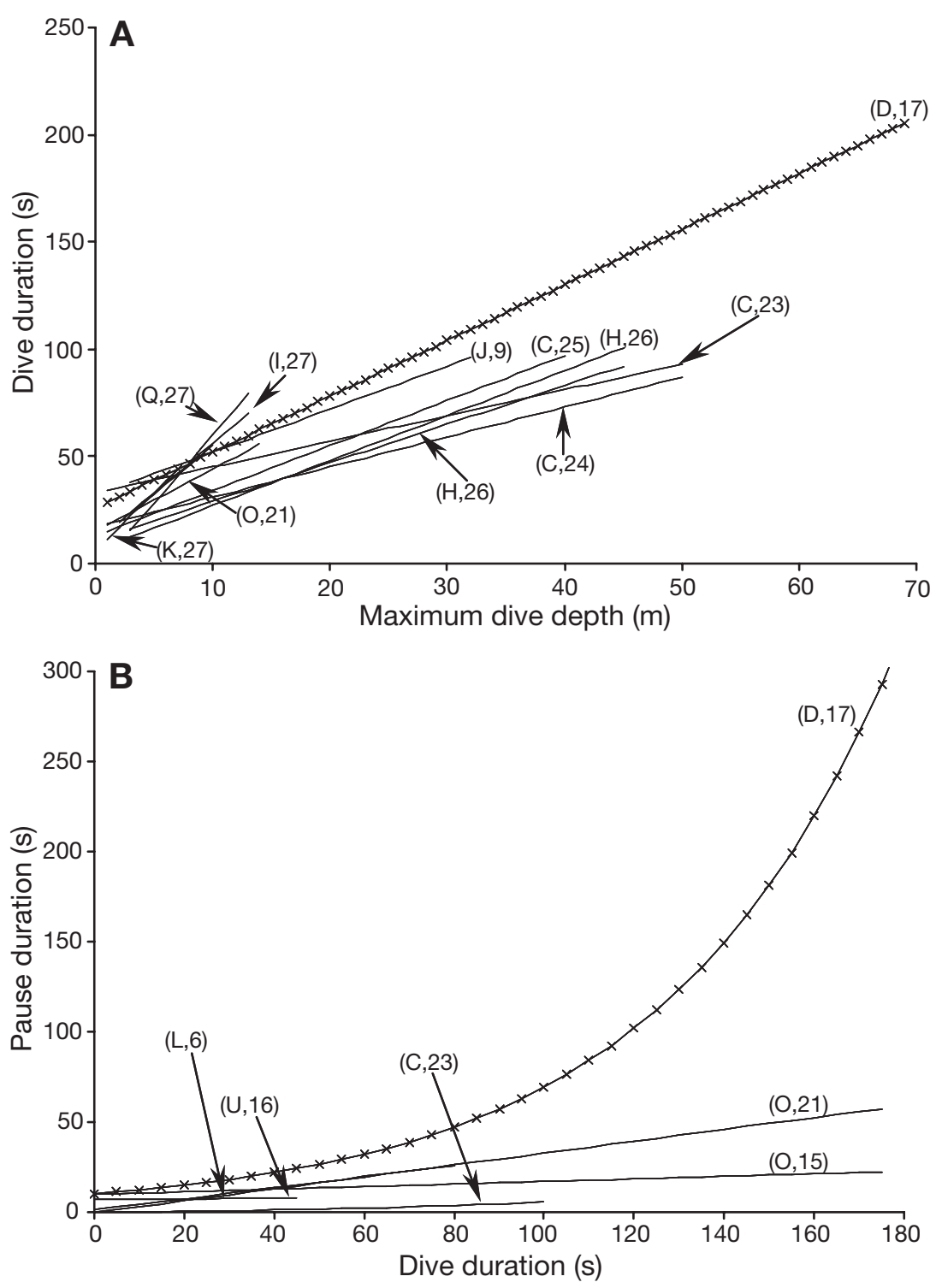

Fig. 5. Relationships between (A) dive duration and depth and (B) interdive (pause) duration and duration of previous dive for various species of cormorants. Lines refer to best-fit regressions presented in the literature and run from min. and max. values given in the source. For ease of identification, our data from Phalacrocorax atriceps (the only blue-eyed species) are shown as $\longrightarrow x$. Letters and numbers refer to species and source (see Fig. 4) species documented in Fig. 5B (note that 3 species were diving in the same general area). We suggest, therefore, that the effects of depth are the primary driver for the observed differences between blue-eyed and other cormorants. Depth is important because depth-dependent pressure affects the volume of air in bird plumage (Lovvorn \& Jones 1991), which in turn affects both the mechanical work required to overcome buoyancy (Lovvorn \& Jones 1991, Lovvorn 1999, 2001) and heat loss (Gremillet et al. 1998b, Enstipp et al. 2006). Indeed, in a recent study, Wilson et al. (2006) noted how overall dynamic body acceleration (ODBA) in great cormorants (as measured by animal-attached accelerometers) correlated closely $\left(r^{2}=0.81\right)$ with rate of oxygen use, and how ODBA in free-living imperial cormorants correlated extremely well $\left(\mathrm{r}^{2}=0.97\right)$ with calculated relative buoyancy.

\section{Effect of plumage air on dive energetics}

The general effect of plumage air on the energetics of diving in cormorants can be simplified by considering the power output required to take bodies with associated air to specific depths. We propose to ignore drag effects because descent speed did not change with depth, and suggest that the conversion by birds of aerobic power input into mechanical power output can be assumed to be roughly constant (SchmidtNielsen 1997). Thus, the upthrust ( $U$, in Newtons) at any given depth is:

$$
U=g(V\{1 /[1+(D / 10.3)]\})
$$

where $V$ is the volume of air at the surface, $D$ is depth (m) and $g$ is the gravitational constant. The power ( $P$, in Watts) required to overcome the upthrust and to move the body down the water column is simply given by the rate of change of depth $(\Delta D / \mathrm{d} t)$ of the volume so that:

$$
P=U(\Delta D / \mathrm{d} t)
$$

Applying this to hypothetical imperial cormorants with a mass of $2 \mathrm{~kg}$ and body density (excluding air) of $1.03 \mathrm{~g} \mathrm{ml}^{-1}$ (Wilson et al. 1992) with, and without, a substantial amount of plumage air $(90 \mathrm{vs} .300 \mathrm{ml}$ $\mathrm{kg}^{-1}$; values representing the minimum documented for cormorants and a value for other divers such as auks or diving ducks [Wilson et al. 1992, Gremillet et al. 2005b] 
descending the water column at an approximate rate of $1.5 \mathrm{~m} \mathrm{~s}^{-1}$ [see above]) indicates that the volume of air contained in the plumage makes a huge difference to mechanical power required for the descent (Fig. 6A). The instantaneous power requirements can be integrated to determine the cumulative mechanical energy needed to take these 2 hypothetical birds down the water column (Fig. 6B), and the division of this energy at any depth by the time taken to reach it can be used to determine the mean mechanical power output necessary for the descent. Again, the difference between the hypothetical bird with much and little air is sub-
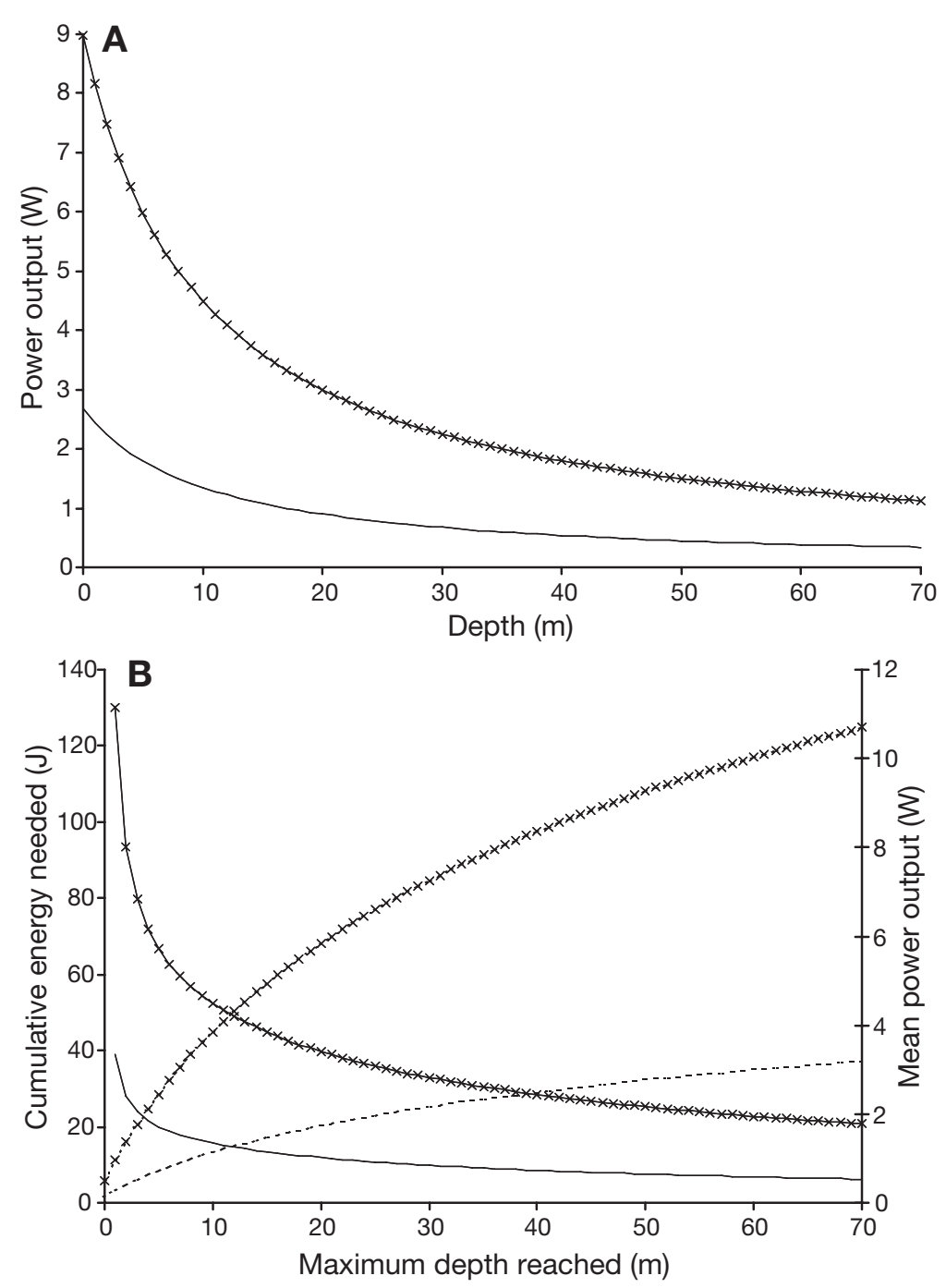

Fig. 6. (A) Instantaneous mechanical power required to descend 2 cormorant bodies, identical in physical characteristics (mass $=2 \mathrm{~kg}$, density $\left.1.03 \mathrm{~g} \mathrm{ml}^{-1}\right)$ except for volume of associated air $\left(-x-300 \mathrm{ml} \mathrm{kg}{ }^{-1}\right.$, $=90 \mathrm{ml} \mathrm{kg}^{-1}$ ), down the water column at a rate of $1.5 \mathrm{~m} \mathrm{~s}^{-1}$ as a function of depth. Note that this does not take into account forces due to drag. (B) Cumulative mechanical energy needed to take the 2 cormorant bodies shown in (A) to a specific depth (rising curves: $\longrightarrow$, bird with $300 \mathrm{ml}$ air $\mathrm{kg}^{-1}$; ------, bird with $90 \mathrm{ml}$ air $\mathrm{kg}^{-1}$ ) and mean power output needed to achieve this (descending curves: $\underset{-}{-}$, bird with $300 \mathrm{ml}$ air $\mathrm{kg}^{-1}$; — with $90 \mathrm{ml}$ air $\mathrm{kg}^{-1}$ ) stantial, differing by a factor of about 3 . This highlights the importance of plumage air volume in modulating the diving energetics, and is borne out by field and captive studies on diving birds for both the descent and bottom phase of the dive (Sato et al. 2002, Lovvorn et al. 2004, Tremblay et al. 2005, Watanuki et al. 2005, 2006, Enstipp et al. 2006, Kato et al. 2006). Thus, a difference in plumage air volume may well account for the differences we observe between imperial and other cormorants not of the blue-eyed group. This effect may be further modulated by variation in the amount of air inhaled prior to diving; it has been noted that some diving birds inhale more when diving deeper (Sato et al. 2002, Wilson \& Zimmer 2004) because respiratory volumemediated upthrust decreases with depth. Thus, deep-diving birds may use more energy to descend; however, it is predicted that the extra oxygen provided by respiratory spaces at the final foraging depth and the passive ascent from a greater depth compensate for this (Wilson \& Zimmer 2004).

The law of heat conduction states that the rate of heat loss is inversely proportional to the thickness of insulation. In the case of cormorants, heat loss to the wateranother major factor modulating metabolic rate (Enstipp et al. 2005, 2006) - will vary linearly with plumage thickness (and therefore volume). Thus, a simplified representation of the benefits and costs to cormorants of swimming along the sea bed at various depths with 2 different amounts of air in their plumage (much air: e.g. $300 \mathrm{ml}$

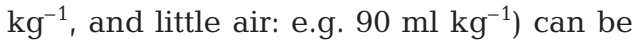
constructed by considering that birds generate a fixed proportion of heat as a result of muscular activity (Schmidt-Nielsen 1997) and that this activity is directly related to upthrust (Fig. 7). This assumes that bird body temperature remains constant (cf. Wilson \& Gremillet 1996, Enstipp et al. 2005). Heat loss from the bird will be determined by the thickness of the plumage (inversely proportional to plumage volume), which varies with depth (Gremillet et al. 1998b) (Fig. 7). If the cormorant swimming along the sea bed is to maintain thermal homeostasis with no cost other than that involved in locomotion, then the heat generated from the effort involved in swimming must always exceed that lost (bird with much plumage air in Fig. 7 up to depths of at least $70 \mathrm{~m}$ ). At depths where 
heat loss exceeds that produced during locomotion, the bird must increase energy expenditure to compensate.

Our model (which is mechanistic, does not incorporate behavioural or physiological complexities that might help regulate heat loss, and instead uses representative values from birds and is intended to show trends rather than absolute values) shows that the energy expended for swimming along the bottom is less for the bird with little plumage air at depths between 0 and $40 \mathrm{~m}$, but less for the bird with much plumage air at deeper depths than this (Fig. 7). This indicates how different plumage characteristics may allow birds competitive advantages at different depths. Substantially increasing energy expenditures in cormorants with little plumage air beyond their critical depth (where heat loss exceeds that generated) would imply that inter-dive surface pauses should increase in an accelerating fashion unless, during such deep dives, body temperature falls. Such decreases in body temperature have been observed in at least some cormorant species (Wilson \& Gremillet 1996) but do not seem to be the norm (Enstipp et al. 2005, Gremillet et al. 2005a). Ultimately, however, either substantial temperature drops during diving or excess heat loss at the surface during extended resting following prolonged diving (when heat generation is minimized) (Enstipp et al. 2005) would be expected to shorten the period over which cormorants with little plumage air can actively remain at sea. This condition will be exacerbated by cold water.

We thus propose that differences in dive performance between cormorants of the blue-eyed taxon stem from differences in plumage air volume, with blue-eyed cormorants having substantially more air in the non-wettable part of the plumage (Gremillet et al. $2005 b)$. There is certainly great interspecific variability in plumage air even among cormorants: for example, Wilson et al. (1992) noted that cape cormorants Phalacrocorax capensis have 3 times as much plumage air per kg body mass as great cormorants P. carbo. Additional support for this proposition derives from 2 other pieces of evidence. Firstly, the stroke frequency of the imperial cormorant descending the water column at a rate of $1.5 \mathrm{~m} \mathrm{~s}^{-1}$ (Fig. 3) was consistently higher than that of similarly sized great cormorants descending the water column at the same rate for any depth (values are ca. 4.5 vs. $3.1 \mathrm{~Hz}$ at $5 \mathrm{~m}, 3.3 \mathrm{vs} .2 .8 \mathrm{~Hz}$ at $10 \mathrm{~m}$ and 2.2 vs. $2.1 \mathrm{~Hz}$ at $20 \mathrm{~m}$ for imperial and great cormorants, respectively; see Kato et al. 2006). However, values were similar to those recorded for the European

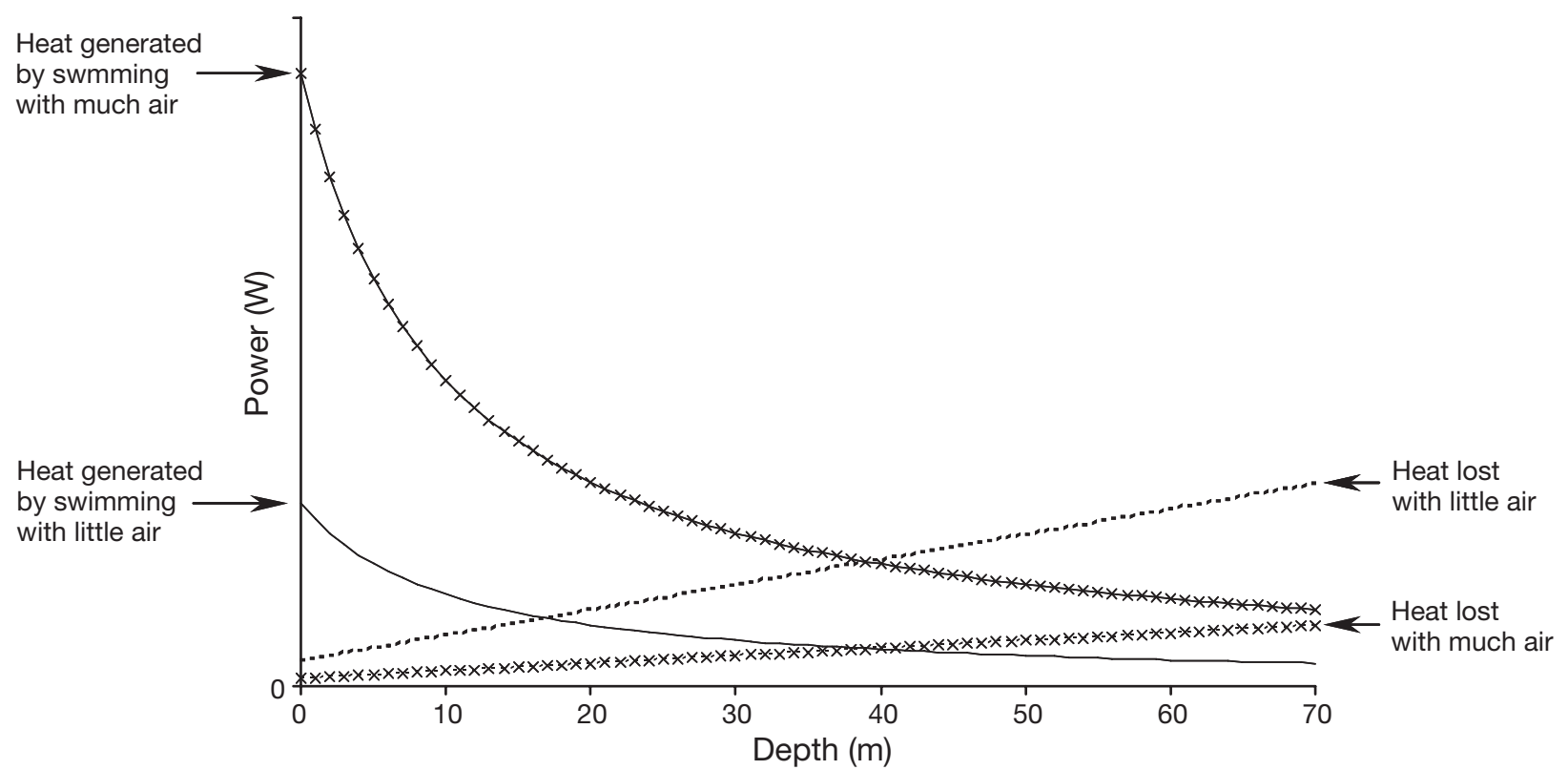

Fig. 7. Heat generation and loss based on mechanical power of 2 cormorants, identical except for amount of air contained in the plumage (much vs. little air), swimming at the sea bed at different depths. Mechanical power calculated assuming that it is linearly related to upthrust, which is itself inversely related to depth (see equation in text). Heat generated by the cormorant with much plumage air (assumed to comprise $70 \%$ of energy used per second) is greater than that of bird with little plumage air over all depths (due to greater power required to counter upthrust); heat loss is also less in the cormorant with much plumage air (following the law of heat conduction, where energy loss is proportional to temperature difference and inversely proportional to the insulating layer). In this scenario, heat lost by the bird with much plumage air never exceeds that generated. The bird with little plumage air loses more heat than it generates at $16 \mathrm{~m}$, and so must generate extra heat to compensate if body temperature is not to drop. At $40 \mathrm{~m}$ and deeper, energy expended by the bird with little plumage air exceeds that of the bird with much plumage air 
shag (Watanuki et al. 2005), a cormorant that also regularly dives to remarkable depths (Wanless et al. 1999). Secondly, although they may forage in water at temperatures close to $0^{\circ} \mathrm{C}$ (Johnsgard 1993), cormorants from the blue-eyed group spend extended periods at sea (e.g. means of between 150 min [our data] and $210 \mathrm{~min}$ [Kato et al. 1992] for P. atriceps, ca. $120 \mathrm{~min}$ for $P$. albiventer [Kato et al. 2000] and $194 \mathrm{~min}$ for $P$. nivalis [Green \& Williams 1997], and up to a maximum of $390 \mathrm{~min}$ [our data]). This contrasts starkly with some other cormorants, notably $P$. carbo, which is known to contain very little plumage air $\left(170 \mathrm{ml} \mathrm{kg}^{-1}\right)$ (Gremillet et al. 2005b) and is limited to a mean daily foraging time of just $9 \mathrm{~min}$ in water at $-2^{\circ} \mathrm{C}$ (but will forage for a daily mean of about $45 \mathrm{~min}$ at $8^{\circ} \mathrm{C}$ and $150 \mathrm{~min}$ at $\left.13^{\circ} \mathrm{C}\right)($ Gremillet et al. 2001, but see Gremillet et al. 2005a). We note again that European shags (which do not belong to the blue-eyed complex) appear atypical, and may spend up to $7 \mathrm{~h} \mathrm{~d}^{-1}$ in northern European waters at temperatures around $9{ }^{\circ} \mathrm{C}$ (Daunt et al. 2006).

Our proposition could be substantiated by determining the volume of air in the plumage of cormorants of this group and examining the feathers according to methods detailed by Gremillet et al. (2005b). However, in order to obtain a reasonable sample size, this approach requires that birds be specifically killed for this purpose, which we felt was not ethically justified.

Our treatise purports that imperial cormorants, together with other members of the blue-eyed group, have plumage that is atypical of cormorants in that it contains substantial amounts of air. It may be that the distribution of blue-eyed cormorants, being limited to the colder waters south of $43^{\circ}$ (Johnsgard 1993), gives these birds a competitive advantage over other cormorants as a result of their better insulation. However, we would expect this advantage to be eroded as water temperatures increase, to instead favour other cormorant species. In higher water temperatures, blue-eyed cormorants could maintain a competitive advantage over other species by diving deeper (and therefore longer) because deep dives expose birds to thermally more stressful environments. In this regard, it is notable that mean dive durations of imperial cormorants studied here (100.4 s) were markedly longer than those reported for rock shags Phalacrocorax magellanicus (47 s) (Quintana 1999), red-legged cormorants P. gaimardi) (26.8 s) (Frere et al. 2002) and neotropic cormorants P. olivaceus (19 s) (Quintana et al. 2004), and that mean maximum depth of birds in this study was between 40 and $115 \%$ greater than those suggested for rock shags (Quintana 1999), red-legged cormorants (Frere et al. 2002) and neotropic cormorants (Quintana et al. 2004), all of which breed sympatrically with imperial cormorants along the Patagonian coast of
Argentina (Frere et al. 2005). However, deep diving must be balanced by appropriate prey densities to make the increased transit time between the surface and bottom profitable. Future studies could address the rates of prey acquisition in cormorants in general (Gremillet et al. 2001, 2004), and in blue-eyed cormorants in particular, in order to determine how prey density with depth equates with appropriate dive strategies and net energetic gain after taking into account the factors that modulate metabolic rate. Other than that, a global examination of the depths and temperatures exploited by various cormorant species in relation to plumage air volume (perhaps facilitated by the simple methods proposed by Wilson et al. 1992) might go some way to help explain patterns of distribution in these remarkable birds.

Acknowledgements. Research was funded by grants from the Wildlife Conservation Society, Consejo Nacional de Investigaciones Científicas y Técnicas de la República Argentina, and Agencia de Promoción Científica y Tecnológica. We thank A. Gatto, N. Lisnizer, R. Vera and M. A. Díaz for field assistance. We also thank Centro Nacional Patagónico (CONICET) for institutional support and Soriano S. A. for logistical support. Thanks to H. Vargas for allowing us to use his unpublished data and to T. Dix for working through dive data related to foot kicks.

\section{LITERATURE CITED}

Bannasch R, Wilson RP, Culik B (1994) Hydrodynamic aspects of design and attachment of a back-mounted device in penguins. J Exp Biol 194:83-96

Bevan RM, Boyd IL, Butler PJ, Reid K, Woakes AJ, Croxall JP (1997) Heart rates and abdominal temperatures of freeranging South Georgian shags, Phalacrocorax georgianus. J Exp Biol 200:661-675

Burger AE (1991) Maximum diving depths and underwater foraging in alcids and penguin. Can Wildl Serv Occ Pap 68:9-15

Casaux R, Favero M, Silva P, Baroni A (2001) Sex differences in diving depths and diet of antarctic shags at the South Shetland Islands. J Field Ornithol 72:22-29

Cooper J (1986) Diving patterns of cormorants Phalacrocoracidae. Ibis 128:562-570

Croxall JP, Naito Y, Kato A, Rothery P, Briggs DR (1991) Diving patterns and performance in the Antarctic Blue-Eyed Shag Phalacrocorax atriceps. J Zool 225:177-199

Daunt F, Afanasyev V, Silk JRD, Wanless S (2006) Extrinsic and intrinsic determinants of winter foraging and breeding phenology in a temperate seabird. Behav Ecol Sociobiol 59:381-388

Enstipp MR, Gremillet D, Lorentsen SF (2005) Energetic costs of diving and thermal status in European shags (Phalacrocorax aristotelis). J Exp Biol 208:3451-3461

Enstipp MR, Gremillet D, Jones DR (2006) The effects of depth, temperature and food ingestion on the foraging energetics of a diving endotherm, the double-crested cormorant (Phalacrocorax auritus). J Exp Biol 209:845-859

Frere E, Quintana F, Gandini P (2002) Diving behavior of the red-legged cormorant in southeastern Patagonia, Argentina. Condor 104:440-444 
Frere E, Quintana F, Gandini P (2005) Cormoranes de la costa patagónica: estado poblacional, ecología y conservación. Hornero 20:35-52

Green K, Williams R (1997) Biology of the Heard Island shag, Phalacrocorax nivalis. 3. Foraging, diet and diving behaviour. Emu 97:76-83

Gremillet D (1997) Catch per unit effort, foraging efficiency, and parental investment in breeding great cormorants (Phalacrocorax carbo carbo). ICES J Mar Sci 54: 635-644

Gremillet D, Wilson RP (1999) A life in the fast lane: energetics and foraging strategies of the great cormorant. Behav Ecol 10:516-524

Gremillet D, Argentin G, Schulte B, Culik BM (1998a) Flexible foraging techniques in breeding cormorants Phalacrocorax carbo and shags Phalacrocorax aristotelis: benthic or pelagic feeding? Ibis 140:113-119

Gremillet D, Tuschy I, Kierspel M (1998b) Body temperature and insulation in diving great cormorants and European shags. Funct Ecol 12:386-394

Gremillet D, Wanless S, Carss DN, Linton D, Harris MP, Speakman JR, Le Maho Y (2001) Foraging energetics of arctic cormorants and the evolution of diving birds. Ecol Lett 4:180-184

Gremillet D, Kuntz G, Delbart F, Mellet M and 6 others (2004) Linking the foraging performance of a marine predator to local prey abundance. Funct Ecol 18:793-801

Gremillet D, Kuntz G, Woakes AJ, Gilbert C, Robin JP, Le Maho Y, Butler PJ (2005a) Year-round recordings of behavioural and physiological parameters reveal the survival strategy of a poorly insulated diving endotherm during the Arctic winter. J Exp Biol 208:4231-4241

Gremillet D, Chauvin C, Wilson RP, Le Maho Y, Wanless S (2005b) Unusual feather structure allows partial plumage wettability in diving great cormorants Phalacrocorax carbo. J Avian Biol 36:57-63

Halsey LG, Butler PJ, Blackburn TM (2006) A phylogenetic analysis of the allometry of diving. Am Nat 167:276-287

Ishikawa K, Watanuki Y (2002) Sex and individual differences in foraging behavior of Japanese cormorants in years of different prey availability. J Ethol 20:49-54

Johnsgard PA (1993) Cormorants, darters, and pelicans of the world. Smithsonian Institute Press, Washington, DC

Kato A, Croxall JP, Watanuki Y, Naito Y (1992) Diving patterns and performance in male and female imperial cormorants, Phalacrocorax atriceps, at South Georgia. Mar Ornithol 19:117-129

Kato A, Naito Y, Watanuki Y, Shaughnessy PD (1996) Diving pattern and stomach temperatures of foraging king cormorants at subantarctic Macquarie Island. Condor 98: $844-848$

Kato A, Watanuki Y, Nishiumi I, Kuroki M, Shaughnessy P, Naito Y (2000) Variation in foraging and parental behavior of king cormorants. Auk 117:718-730

Kato A, Ropert-Coudert Y, Gremillet D, Cannell B (2006) Locomotion and foraging strategy in foot-propelled and wing-propelled shallow-diving seabirds. Mar Ecol Prog Ser 308:293-301

Lea SEG, Daley C, Boddington PJC, Morison V (1996) Diving patterns in shags and cormorants (Phalacrocorax): tests of an optimal breathing model. Ibis 138:391-398

Lovvorn JR (1999) Effects of dive depth, buoyancy, and propulsive mode on the inertial work of swimming in birds. Am Zool 39:14

Lovvorn JR (2001) Upstroke thrust, drag effects, and strokeglide cycles in wing-propelled swimming by birds. Am Zool 41:154-165
Lovvorn JR, Jones DR (1991) Effects of body size, body fat, and change in pressure with depth on buoyancy and costs of diving in ducks (Aythya spp). Can J Zool 69:2879-2887

Lovvorn JR, Watanuki Y, Kato A, Naito Y, Liggins GA (2004) Stroke patterns and regulation of swim speed and energy cost in free-ranging Brunnich's guillemots. J Exp Biol 207: 4679-4695

Malacalza VE, Hall MA (1988) Sexing adult king cormorants (Phalacrocorax albiventer) by discriminant analysis. Colon Waterbirds 11:32-37

Orta J (1992) Family Phalacrocoracidae (cormorants). In: del Hoyo J, Elliott A, Sartagal J (eds) Handbook of the birds of the world, Vol 1. Lynx Ediciones, Barcelona, p 326-353

Quintana F (1999) Diving behavior of rock shags at a Patagonian colony of Argentina. Waterbirds 22:466-471

Quintana F, Yorio P, Lisnizer N, Gatto A, Soria G (2004) Diving behavior and foraging areas of the neotropic cormorant at a marine colony in Patagonia, Argentina. Wilson Bull 116:83-88

Ribak G, Weihs D, Arad Z (2005) Water retention in the plumage of diving great cormorants Phalacrocorax carbo sinensis. J Avian Biol 36:89-95

Sapoznikow A, Quintana F (2003) Foraging behavior and feeding locations of imperial cormorants and rock shags breeding sympatrically in Patagonia, Argentina. Waterbirds 26:184-191

Sato K, Naito Y, Kato A, Niizuma Y and 5 others (2002) Buoyancy and maximal diving depth in penguins: do they control inhaling air volume? J Exp Biol 205:1189-1197

Schmid D, Gremillet DJH, Culik BM (1995) Energetics of underwater swimming in the great cormorant (Phalacrocorax carbo sinensis). Mar Biol 123:875-881

Schmidt-Nielsen K (1997) Animal physiology: adaptation and environment. Cambridge University Press, Cambridge

Schreer JF, Kovacs KM (1997) Allometry of diving capacity in air-breathing vertebrates. Can J Zool 75:339-358

Schreer JF, Kovacs KM, Hines RJO (2001) Comparative diving patterns of pinnipeds and seabirds. Ecol Monogr 71: 137-162

Tremblay Y, Cook TR, Cherel Y (2005) Time budget and diving behaviour of chick-rearing Crozet shags. Can J Zool 83:971-982

Wanless S, Harris MP (1991) Diving patterns of full-grown and juvenile rock shags. Condor 93:44-48

Wanless S, Harris MP, Morris JA (1992) Diving behavior and diet of the blue-eyed shag at South Georgia. Polar Biol 12: 713-719

Wanless S, Corfield T, Harris MP, Buckland ST, Morris JA (1993) Diving behavior of the shag Phalacrocorax aristotelis (Aves, Pelecaniformes) in relation to water depth and prey size. J Zool 231:11-25

Wanless S, Harris MP, Morris JA (1995) Factors affecting daily activity budgets of South Georgian shags during chick rearing at bird island, South Georgia. Condor 97:550-558

Wanless S, Finney SK, Harris MP, McCafferty DJ (1999) Effect of the diel light cycle on the diving behaviour of two bottom feeding marine birds: the blue-eyed shag Phalacrocorax atriceps and the European shag P. aristotelis. Mar Ecol Prog Ser 188:219-224

Watanuki Y, Kato A, Naito Y (1996) Diving performance of male and female Japanese cormorants. Can J Zool 74: 1098-1109

Watanuki Y, Takahashi A, Daunt F, Wanless S, Harris M, Sato K, Naito Y (2005) Regulation of stroke and glide in a footpropelled avian diver. J Exp Biol 208:2207-2216

Watanuki Y, Wanless S, Harris M, Lovvorn JR, Miyazaki M, Tanaka H, Sato K (2006) Swim speeds and stroke patterns 
in wing-propelled divers: a comparison among alcids and a penguin. J Exp Biol 209:1217-1230

Wilson RP, Gremillet D (1996) Body temperatures of freeliving African penguins (Spheniscus demersus) and bank cormorants (Phalacrocorax neglectus). J Exp Biol 199: 2215-2223

Wilson RP, Quintana F (2004) Surface pauses in relation to dive duration in imperial cormorants: how much time for a breather? J Exp Biol 207:1789-1796

Wilson RP, Wilson MPT (1988) Foraging behaviour in 4 sympatric cormorants. J Anim Ecol 57:943-955

Wilson RP, Zimmer I (2004) Inspiration by Magellanic penguins: reduced swimming effort when under pressure. Mar Ecol Prog Ser 278:303-307

Editorial responsibility: Howard Browman (Associate Editorin-Chief), Storebø, Norway
Wilson RP, Hustler K, Ryan PG, Burger AE, Noldeke EC (1992) Diving birds in cold water-do Archimedes and Boyle determine energetic costs? Am Nat 140:179-200

Wilson RP, White CR, Quintana F, Halsey LG, Liebsch N, Martin GR, Butler PJ (2006) Moving towards acceleration for estimates of activity-specific metabolic rates in free-living animals: the case of the cormorant. J Anim Ecol 75: 1081-1090

Yorio P, Frere P, Gandini P, Harris G (1998) Atlas de la distribución reproductiva de aves marinas en el litoral patagónico Argentino. Fundación Patagonia Natural and Wildlife Conservation Society, Puerto Madryn

Zabalaga CB, Paredes R (1999) Foraging behaviour and diet of the guanay cormorant. S Afr J Mar Sci 21:251-258

Submitted: May 16, 2006; Accepted: August 14, 2006 Proofs received from author(s): March 6, 2007 